\title{
BMJ Open Gender disparity between authors in leading medical journals during the COVID-19 pandemic: a cross- sectional review
}

\author{
Vaidehi Misra, ${ }^{1}$ Frozan Safi, ${ }^{2}$ Kathryn A Brewerton, ${ }^{2}$ Wei Wu, ${ }^{1}$ Robin Mason (D) , $, 1,4$ \\ An-Wen Chan, ${ }^{1,2,5,6}$ Paula A Rochon (1D , ${ }^{1,2,5,6}$ Iliana C Lega (D) , ${ }^{1,2,5}$ \\ Husam Abdel-Qadir (iD) 1,2,5,6,7
}

To cite: Misra V, Safi F, Brewerton KA, et al. Gender disparity between authors in leading medical journals during the COVID-19 pandemic: a crosssectional review. BMJ Open 2021;11:e051224. doi:10.1136/ bmjopen-2021-051224

- Prepublication history and additional supplemental material for this paper are available online. To view these files, please visit the journal online (http://dx.doi.org/10.1136/ bmjopen-2021-051224)

ICL and $\mathrm{HA}-\mathrm{Q}$ contributed equally.

Received 14 March 2021 Accepted 25 June 2021

Check for updates

(C) Author(s) (or their employer(s)) 2021. Re-use permitted under CC BY-NC. No commercial re-use. See rights and permissions. Published by BMJ.

For numbered affiliations see end of article.

Correspondence to Dr Husam Abdel-Qadir; h.abdel.qadir@utoronto.ca

\section{ABSTRACT}

Objectives Evaluate gender differences in authorship of COVID-19 articles in high-impact medical journals compared with other topics.

Design Cross-sectional review.

Data sources Medline database.

Eligibility criteria Articles published from 1 January to 31 December 2020 in the seven leading general medical journals by impact factor. Article types included primary research, reviews, editorials and commentaries.

Data extraction Key data elements were whether the study topic was related to COVID-19 and names of the principal and the senior authors. A hierarchical approach was used to determine the likely gender of authors. Logistic regression assessed the association of study characteristics, including COVID-19 status, with authors' likely gender; this was quantified using adjusted $\mathrm{ORs}$ (aORs).

Results We included 2252 articles, of which 748 (33.2\%) were COVID-19-related and 1504 (66.8\%) covered other topics. A likely gender was determined for $2138(94.9 \%)$ principal authors and 1890 (83.9\%) senior authors. Men were significantly more likely to be both principal (1364 men; $63.8 \%$ ) and senior (1332 men; 70.5\%) authors. COVID-19related articles were not associated with the odds of men being principal (aOR $0.99 ; 95 \% \mathrm{Cl} 0.81$ to $1.21 ; \mathrm{p}=0.89$ ) or senior authors (aOR $0.96 ; 95 \% \mathrm{Cl} 0.78$ to $1.19 ; \mathrm{p}=0.71$ ) relative to other topics. Articles with men as senior authors were more likely to have men as principal authors $(\mathrm{aOR}$ $1.49 ; 95 \% \mathrm{Cl} 1.21$ to $1.83 ; p<0.001)$. Men were more likely to author articles reporting original research and those with corresponding authors based outside the USA and Europe. Conclusions Women were substantially under-represented as authors among articles in leading medical journals; this was not significantly different for COVID-19-related articles. Study limitations include potential for misclassification bias due to the name-based analysis. Results suggest that barriers to women's authorship in high-impact journals during COVID-19 are not significantly larger than barriers that preceded the pandemic and that are likely to continue beyond it. PROSPERO registration number CRD42020186702.

\section{INTRODUCTION}

The COVID-19 pandemic has created an unprecedented global crisis, necessitating

\section{Strengths and limitations of this study}

- The study used a systematic approach to study gender disparity in authorship of articles published in medical journals with the highest impact factor during the 2020 calendar year during which the COVID-19 pandemic began.

- The study predominantly relied on a name-based analysis, which may lead to misclassification of nonbinary authors and those with non-Western names.

- The study was limited to studying authorship of high-impact medical journals and does not address other aspects of academic productivity.

- The analysis does not account for a potentially lower proportion of female-to-male researchers in the medical sciences.

the generation of new knowledge and novel solutions to address the challenges it has produced. The pandemic has also forced societies to adopt physical distancing measures that include widespread work-from-home policies ${ }^{12}$ and closure of schools and daycare centres, leading to increased family caregiving needs. ${ }^{34}$ This is more likely to have affected women, since they traditionally shoulder a disproportionate burden of household and caregiving responsibilities. ${ }^{3}$

The need for solutions to the challenges created by COVID-19 has resulted in valuable academic opportunities within the medical sciences. The short window to pivot towards COVID-19 research, coupled with the barriers experienced disproportionately by women, has contributed to greater uptake of COVID19-related academic opportunities by men. ${ }^{35-8}$ Preliminary analyses of American medical publications suggest that female principal authors' publishing rates have dropped 19\% during the pandemic when compared with the previous year. ${ }^{9}$ High-impact publications 
are important measures of academic productivity and hold implications for academic promotion, research funding and other professional opportunities. ${ }^{10-13}$ It has been demonstrated that, in general, men are more likely than women to publish in high-impact medical journals. ${ }^{14}$ It remains unclear if this disparity extends to the novel realm of COVID-19-related publications.

Accordingly, we conducted a cross-sectional review of articles published during the 2020 calendar year in highimpact medical journals to study gender differences in authorship of COVID-19 articles, with comparison to articles about other medical topics during the same period. We hypothesised that COVID-19-related publications were more likely to have men as principal and senior authors (rather than women). We also hypothesised that the gender-associated disparity in principal and senior authorships would be more pronounced for COVID-19related articles compared with those about other medical topics.

\section{METHODS}

We used the Clarivate 2019 Journal Citation Reports ${ }^{15}$ to identify the seven general medical journals with the highest impact factors: the New England Journal of Medicine (NEJM), the Lancet, the Journal of the American Medical Association (JAMA), Nature Medicine, the BMJ, Annals of Internal Medicine and JAMA Internal Medicine (Nature Reviews Disease Primers was excluded since it predominantly publishes review articles). We searched the Medline database for all articles published in these journals between 1 January 2020 and 31 December 2020 using the PubMed platform. These dates were chosen to cover the period immediately before the institution of widespread school closures and work-from-home policies, in addition to the months following these changes. ${ }^{16-21} \mathrm{We}$ included article types that reported primary research, reviews, editorials and commentaries. Other article types such as anecdotes, creative writing pieces and news were excluded. The specific included/excluded article types from each journal are provided in online supplemental table 1 . The following search strategy was used:

( (( ( ((“The New England journal of medicine" [Journal]) OR ("the lancet"[Journal]))

OR ("JAMA"[Journal])) OR ("British medical journal"[Journal])) OR ("Nature medicine"[Journal])) OR ("Annals of internal medicine"[Journal])) OR ("JAMA internal medicine"[Journal])) AND

$$
\begin{aligned}
& \text { ((“2020/01/01”[Date - Publication] } \\
& \text { "2020/12/31"[Date - Publication] )) }
\end{aligned}
$$

The Covidence data extraction tool (https://www. covidence.org/) was used to facilitate article selection and data collection. The key data elements extracted were whether the study topic was related to COVID-19 (or not) and the names of the principal author and the senior author (where applicable). The first-listed author was classified as the principal author, while the last-listed author was classified as the senior author, as authorship order in most medical journals correlates with levels of contributions. ${ }^{12} 13$ The Genderize tool (https://genderize.io/) was used to determine the likely gender of the author based on their first name, using a $90 \%$ probability threshold to determine the likely gender. This tool has been applied in multiple studies examining gender differences in research output. ${ }^{22-25}$ If the probability was $<90 \%$, the author's institutional website was reviewed to determine the author's likely gender. Since Chinese first names are not gender-specific, reviewers fluent in the relevant dialect used the Chinese-language version of institutional website to determine the likely gender of the author based on review of the name in Chinese characters. If a likely gender could not be assigned after this hierarchical approach, it was classified as 'undetermined'. If a specific author was not provided (eg, a research or editorial team was listed), then the author gender was classified as 'not provided'. Additional data collected included the article type and the country where the institution of the corresponding author was based. For articles where the corresponding authors listed multiple countries, the article was categorised as an 'international collaboration'.

\section{Statistical analyses}

The characteristics of included articles were summarised using counts (with percentages). We determined the proportion of likely women and men as principal and senior authors. We categorised articles based on whether the topic was related to COVID-19 or other medical topics. Articles were also categorised as primary research articles (original research or systematic reviews/metaanalyses) or non-research articles (narrative reviews, other reviews, editorials or commentaries). We used logistic regression to study the univariable relationship between COVID-19 study status (ie, COVID-19-related vs other medical topics) and the likely gender of the principal author (which served as the model outcome). The analysis was repeated in separate models to study the association of COVID-19 study status with senior authorship. We then studied the association between COVID-19 study status and the likely gender of principal and senior author while adjusting for the location of the publishing institution (the USA, Europe or others) and primary research versus non-research articles. The likely gender of the senior author was also included as a covariate in the model analysing predictors of the likely gender of the principal author.

We conducted a sensitivity analysis where we excluded studies for which author's likely gender could only be determined by review of an institutional website that was not published in English, given the greater potential for misclassification bias. All analyses were conducted using 
SAS V.9.4 and were two-tailed, with the threshold for statistical significance set at 0.05 .

\section{RESULTS}

\section{Included publications}

We identified 2252 publications that met our inclusion criteria (flow diagram provided in online supplemental figure 1). Most publications reviewed $(\mathrm{n}=1194 ; 53.0 \%)$ were original research or systematic reviews articles (see online supplemental figure 2). A total of 30 (1.3\%) publications were categorised as international collaborations. The location of the corresponding author's institution could not be determined for $75(3.3 \%)$ publications as they were authored by teams without specifying an institution for the corresponding author. Of the remaining 2147 (95.3\%) publications, the corresponding authors were associated with institutions from the USA in 1160 (54.0\%) publications, the UK in $360(16.8 \%)$ publications and other European countries in 232 (10.8\%) publications (see online supplemental figure 3 ). In total, there were $748(33.2 \%)$ COVID-19-related articles and 1504 $(66.8 \%)$ articles that were not related to COVID-19 (see online supplemental figure 2).

\section{Likely genders of authors}

Of the 2252 included publications, 104 (4.6\%) attributed authorship to a team, rather than an individual, while a likely gender of the principal author could not be determined for $10(0.4 \%)$ articles. Among the remaining $2138(94.9 \%)$ articles where the likely gender of the principal author could be determined, the proportion of likely male principal authors ( $\mathrm{n}=1364$ articles; $63.8 \%$ ) was markedly higher than likely women $(n=774 ; 36.2 \%)$. There were $355(15.8 \%)$ articles that were authored by a single person, who we categorised as a principal author (ie, no senior author). Of the 1897 publications that listed a senior author, this was attributed to a team, rather than an individual, in six $(0.3 \%)$ articles, and the likely gender of the senior author could not be determined for one $(0.05 \%)$ article. Among the remaining 1890 (99.6\%) articles, the proportion of likely male senior authors $(n=1332$ articles; $70.5 \%$ ) was more than twice that of likely women $(\mathrm{n}=558 ; 29.5 \%)$.

There were 685 publications related to COVID-19 for which the likely gender of the principal author could be determined (see figure 1). Within these articles, the principal authors were likely men in $441(64.3 \%)$ articles and likely women in $244(35.6 \%)$ articles. For articles unrelated to COVID-19, the principal author's likely gender could be determined for 1453 articles. The principal authors were likely men in $923(63.5 \%)$ articles and likely women in $530(36.5 \%)$ articles. These results are summarised in figure 1.

Shifting to senior authorship, the likely gender of the senior author could be determined for 618 COVID-19related articles. Within these articles, the senior authors were likely men in $431(69.7 \%)$ articles and likely women in $187(30.3 \%)$ articles. There were 1272 articles unrelated to COVID-19 where the likely gender of the senior author could be determined; they were likely men in 901 $(70.8 \%)$ articles and likely women in $371(29.2 \%)$ articles. These results are summarised in figure 2.

\section{Predictors of likely author gender}

Univariable logistic regression showed that there was no significant association between the subject of an article (COVID-19 or other medical topics) and the author's likely gender. The univariable OR that a COVID-19-related publication was authored by a man (relative to articles on other topics) was 0.99 (95\% CI 0.81 to $1.21 ; \mathrm{p}=0.90)$ for principal authors and 0.95 (95\% CI 0.77 to 1.17 ; $\mathrm{p}=0.62)$ for senior authors. After multivariable regression, there remained no association between COVID-19 status and the likely gender of the principal author (see table 1) or

\section{Likely Gender of Principal Authors Among Non-COVID-19 and COVID-19 Publications}

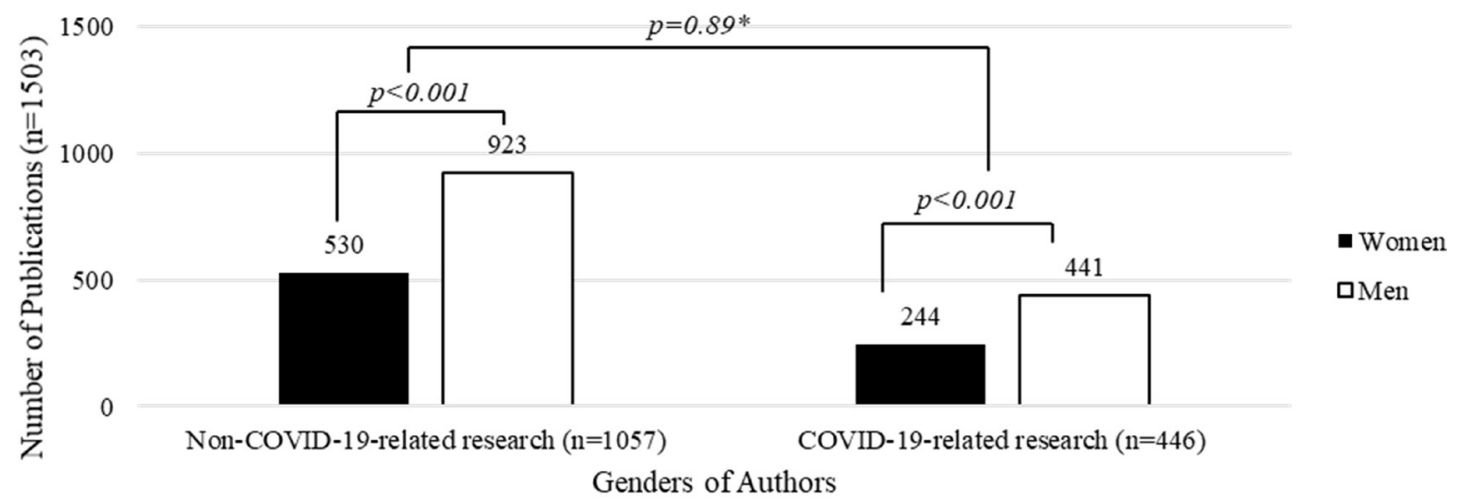

*p-value from logistic regression model that has been adjusted for the likely sex of the senior author, research article type, and location of corresponding author's institution.

Figure 1 Principal authors' likely genders identified among non-COVID-19 and COVID-19-related publications (submitted as separate file). 


\section{Likely Gender of Senior Authors Among Non-COVID-19 and COVID-19 Publications}

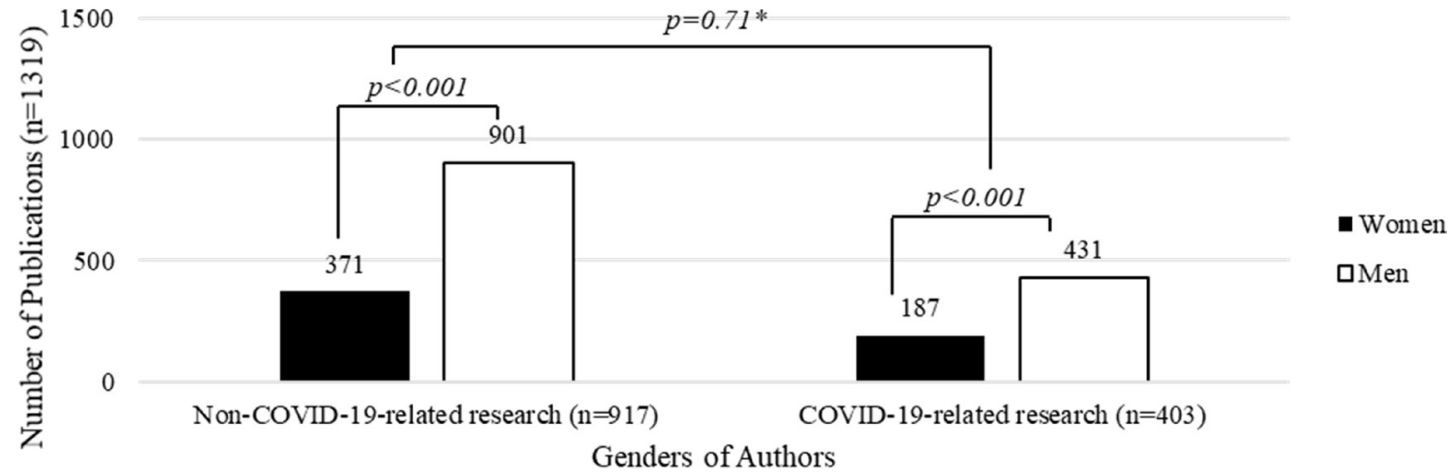

* p-value from logistic regression model that has been adjusted for research article type and location of corresponding author's institution.

Figure 2 Senior authors' likely genders identified among non-COVID-19-related and COVID-19-related publications (submitted as separate file).

senior author (see table 2). In contrast, the likely gender of the senior author was significantly correlated with the likely gender of the principal author. When the senior author was likely a man, the adjusted OR for a likely male principal authors was 1.49 (95\% CI 1.21 to 1.83 ; $\mathrm{p}<0.001)$.

Among all publications reviewed (regardless of topic), those published by corresponding authors based in the USA were less likely to have men as principal authors (adjusted OR $0.80 ; 95 \%$ CI 0.65 to $1.00 ; \mathrm{p}=0.046$ ) or senior authors (adjusted OR 0.79; 95\% CI 0.63 to 1.00; $\mathrm{p}=0.046$ ) compared with those outside the USA or Europe (please see table 1). Furthermore, articles reporting original research or systematic reviews were significantly more likely than non-research articles to have men as principal authors (adjusted OR 1.27; 95\% CI 1.05 to $1.54 ; \mathrm{p}=0.02$ ) or senior authors (adjusted OR 1.55; 95\% CI 1.27 to 1.90; $\mathrm{p}<0.001)$.

\section{Sensitivity analysis}

The sensitivity analysis included 2216 articles where determination of likely author gender did not require review of a non-English website. A likely gender could be determined for the principal author in 2108 articles, of whom $1342(63.7 \%)$ were likely men. A likely gender could be determined for the senior author in 1854 articles, of whom $1303(70.3 \%)$ were likely men. There was no significant difference in the likelihood of authorship by men based on the COVID-19 status of the study. The univariable OR for the association of COVID-19 status with likely principal authorship by men was 0.98 (95\% CI 0.80 to $1.20 ; \mathrm{p}=0.86)$. After multivariable adjustment, the OR was 0.99 (95\% CI 0.81 to $1.21 ; p=0.91$; see online supplemental table 2 ). For the senior author position, the corresponding univariable OR was $0.92(95 \%$ CI 0.75 to 1.14; $\mathrm{p}=0.47)$, while the multivariable OR was $0.95(95 \%$ CI 0.76 to 1.18 ; $\mathrm{p}=0.62$; see online supplemental table 3 ).

\section{DISCUSSION}

In this cross-sectional review, we observed that the proportion of principal and senior authors who were likely men greatly outnumbered that of likely women, both for primary research and non-research articles. Contrary to our hypothesis, we did not find a significant association between the COVID-19 status of an article and the likely gender of authors. On multivariable analysis, the strongest predictor of a man being the primary author was having a man as the senior author. Men were also more likely to author articles reporting original research

Table 1 Summary of the results of multivariable logistic regression examining the association of study characteristics with the odds that the principal author is a man

\begin{tabular}{llll}
\hline Parameter & OR & 95\% Cl & P value \\
\hline COVID-19-related article & 0.99 & 0.81 to 1.21 & 0.89 \\
\hline Man as senior author & 1.49 & 1.21 to 1.83 & $<0.001$ \\
\hline Original research or systematic review* & 1.27 & 1.05 to 1.54 & 0.02 \\
\hline Corresponding author located in the USA† & 0.80 & 0.65 to 1.00 & 0.046 \\
\hline Corresponding author located in Europe† & 1.02 & 0.76 to 1.38 \\
\hline
\end{tabular}

${ }^{*}$ Relative to articles not reporting primary research.

†Relative to institutions not based in the USA or Europe. 
Table 2 Summary of the results of multivariable logistic regression examining the association of study characteristics with the odds that the senior author is a man

\begin{tabular}{llll}
\hline Parameter & OR & $\mathbf{9 5 \%} \mathbf{C l}$ & $\mathbf{P}$ value \\
\hline COVID-19-related article & 0.96 & 0.78 to 1.19 & 0.71 \\
\hline Original research or systematic review* & 1.55 & 1.27 to 1.90 & $<0.001$ \\
Corresponding author located in the USA† & 0.79 & 0.63 to 1.00 & 0.046 \\
\hline Corresponding author located in Europe† & 1.11 & 0.81 to 1.52 \\
\hline
\end{tabular}

${ }^{*}$ Relative to articles not reporting primary research.

†Relative to institutions not based in the USA or Europe.

and systematic reviews (vs non-research articles) and to author articles with corresponding authors based outside the USA and Europe.

Our data demonstrate persistent patterns where men are substantially more likely to publish in high-impact medical journals compared with women. A previous analysis of publications from high-impact journals from February 1994 to June 2014 reported that only $34 \%$ of articles had women as principal authors. ${ }^{14}$ After adjustment, the proportion of women as principal authors increased significantly from $27 \%$ in 1994 to $37 \%$ in 2014 (p<0.001). ${ }^{14}$ Our data move the conversation further by highlighting that the disparity extends to the senior author position and to the new field of COVID-19 research.

The COVID-19 pandemic and the associated lockdowns have heightened pre-existing gender-based inequities in academia. ${ }^{5} 27$ This was partly mediated by gender differences in household and family care responsibilities, which are often predominantly shouldered by women rather than men. ${ }^{28-30}$ Furthermore, men may be more likely to overvalue their abilities at clinical practice and research relative to women. ${ }^{22}$ 31-37 Such factors may provide men with the time and confidence to pivot their research towards a new track focused on COVID-19, where very few people have prior experience. According to a recent review of articles indexed in the Medline database, women accounted for only a third of authors who published COVID-19-related articles since the beginning of the outbreak in January 2020. ${ }^{26} 38$ Women were also less likely to apply to funding competitions that were launched to support COVID-19 research and less likely to receive the allotted funding. ${ }^{78}$ Furthermore, an analysis of science, technology, engineering and mathematics papers submitted to preprint servers concluded that women submitted publications at reduced rates during the COVID-19-associated lockdowns compared with prior years. ${ }^{5}$ Similarly, another analysis of preprint repositories also observed a decrease in submissions by women, which was particularly pronounced among principal authors. ${ }^{6}$

Prior studies on gender-based differences in academic productivity did not specifically study COVID-19-related publications relative to articles on other medical topics. Despite the disproportionately negative impact of COVID-19 on women in research, we observed that the proportion of women as authors in high-impact journals was not significantly different for COVID-19-related articles compared with articles on other medical topics. Similarly, analyses of R01-equivalent applications to the US National Institutes of Health between May 1 and June 5 between 2017 and 2020 demonstrated a comparable degree of under-representation of women among principal applicants compared with prior years $(25.7 \%$ in 2020, compared with $24.6 \%-26.4 \%$ in $2017-2019){ }^{7}$ An important finding is that women are significantly less likely to be principal authors when men are the senior author. This is congruent with literature within the medical sciences, which demonstrates a gender association between principal and senior authors. ${ }^{39} 40$ This holds important implications for women at the early career researcher stage and may contribute to their 'leakage' from the academic pipeline, wherein women are less likely to climb institutional ranks and their ascent occurs at a slower rate if it occurs. ${ }^{11234142}$ Inequitable access to effective mentorship has been cited as a contributing factor to this pattern of women being filtered out as the academic ranks rise. ${ }^{23244344}$

The major implication of this review is that the substantial difficulty experienced by women as researchers during the pandemic may not be markedly larger than the barriers that they were already facing before COVID-19. Rather, the pandemic has highlighted the omnipresent social and structural factors that have contributed to inequitable opportunities for academic success for women. ${ }^{14}$ It is important to recognise that these underlying factors are long-term issues that preceded COVID-19 and are likely to continue after the pandemic has passed. The disparity in publication output that is independent of COVID-19 has important long-term implications beyond the pandemic since publication records continue to be used as a primary measure of success in academia, despite their limitations as a metric of academic output. $^{1011}$ Women produce fewer academic publications than men and receive less citations per publication produced. ${ }^{23} 45-47$ The disparities in publication records may be compounded by the different approaches used by researchers in presenting and promoting their research. Women in the life sciences are less likely to use language such as 'novel' or 'excellent' when describing the significance of their research. ${ }^{22}$ This trend is strongest in high-impact journals where women are $21.4 \%$ 
less likely to present their work positively compared with men and contributes, in part, to fewer citations than men. ${ }^{22}$ Thus, the discussion about the underlying disparities and the search for solutions needs to take a wider lens that focuses on addressing long-lasting systemic and structural disparities rather than focusing solely on transient COVID-19-related factors.

\section{Limitations}

A major limitation of the study is its reliance on namebased analysis, which has the potential to exclude people who identify as non-binary and misidentify other individuals. We were cognizant of this issue and tried to maintain transparency by referring to our classifications as 'likely male/men' or 'likely female/women' throughout the study. The author's gender identity can evolve, and their name, often assigned at birth corresponding to sex, may not necessarily reflect the gender of the adult. Moreover, the Genderize tool is limited in its ability to determine gender associated with non-Western names due to data and cultural considerations. ${ }^{48}$ Native-language speakers have demonstrated success in identifying the gender associated with these names, especially when in written form. ${ }^{48}$ Another limitation is an implicit underlying assumption that the work put into most articles unrelated to COVID-19 that were published in 2020 began before the onset of the pandemic. Thus, the timelines of our search may not be sufficient to paint a full picture of the impact of COVID-19 on gender-related differences in high-impact publications. We cannot wholly attribute the observed sex disparity in authorship to the structural and social factors discussed above. While women are similarly represented in medical degrees or doctorates in the life sciences, ${ }^{49}{ }^{50}$ as well as in residency and postdoctoral training positions, ${ }^{50} 51$ they remain under-represented in faculty positions. ${ }^{24} 44$ Thus, the disparity in female and male principal and senior authors may be partly attributed to the lower proportion of female-to-male researchers in the medical sciences, particularly in higher-ranking positions. ${ }^{11234144}$

\section{CONCLUSION}

Women were significantly less likely than men to be the primary or senior authors in publications in the seven general medical journals with the highest impact factor between 1 January 2020 and 31 December 2020. The under-representation of women was not significantly different between COVID-19-related articles and those on other medical topics. There was a significant positive correlation between the likely gender of the principal and senior author. This analysis highlights that efforts to address gender disparities in academia need to focus on addressing pre-existing structural inequities with longterm lens rather than focusing exclusively on COVID-19specific barriers.
Author affiliations

${ }^{1}$ Women's College Research Institute (WCRI), Women's College Hospital, Toronto, Ontario, Canada

${ }^{2}$ Department of Medicine, University of Toronto, Toronto, Ontario, Canada ${ }^{3}$ Dalla Lana School of Public Health, University of Toronto, Toronto, Ontario, Canada ${ }^{4}$ Department of Psychiatry, University of Toronto, Toronto, Ontario, Canada ${ }^{5}$ ICES, Toronto, Ontario, Canada

${ }^{6}$ Institute of Health Policy, Management, and Evaluation (IHPME), University of Toronto, Toronto, Ontario, Canada

${ }^{7}$ Peter Munk Cardiac Centre (PMCC), University Health Network (UHN), Toronto, Ontario, Canada

Twitter Paula A Rochon @RochonPaula, Iliana C Lega @llianaLega and Husam Abdel-Qadir @husam247

Contributors The corresponding author attests that all listed authors meet authorship criteria and that no others meeting the criteria have been omitted. $\mathrm{HA}-\mathrm{Q}$ and ICL conceived the study and designed the methods. HA-Q prepared and analysed the data with input from VM, FS, KAB, WW, RM, A-WC, PAR and ICL. VM, $F S$, KAB, WW, RM, A-WC, PAR, ICL and HA-Q contributed to interpreting the data. $H A-Q$ and VM drafted the manuscript with substantial input from ICL. All authors contributed to and approved the final manuscript.

Funding $H A-Q$ is supported by the National New Investigator Award from the Heart and Stroke Foundation of Canada.

Competing interests None declared.

Patient and public involvement statement It was not possible to involve patients or the public in the design, conduct or reporting of this study. We intend to disseminate the findings of this research to the public.

Patient consent for publication Not required.

Provenance and peer review Not commissioned; externally peer reviewed.

Data availability statement Data are available upon reasonable request.

Supplemental material This content has been supplied by the author(s). It has not been vetted by BMJ Publishing Group Limited (BMJ) and may not have been peer-reviewed. Any opinions or recommendations discussed are solely those of the author(s) and are not endorsed by BMJ. BMJ disclaims all liability and responsibility arising from any reliance placed on the content. Where the content includes any translated material, BMJ does not warrant the accuracy and reliability of the translations (including but not limited to local regulations, clinical guidelines, terminology, drug names and drug dosages), and is not responsible for any error and/or omissions arising from translation and adaptation or otherwise.

Open access This is an open access article distributed in accordance with the Creative Commons Attribution Non Commercial (CC BY-NC 4.0) license, which permits others to distribute, remix, adapt, build upon this work non-commercially, and license their derivative works on different terms, provided the original work is properly cited, appropriate credit is given, any changes made indicated, and the use is non-commercial. See: http://creativecommons.org/licenses/by-nc/4.0/.

\section{ORCID iDs}

Robin Mason http://orcid.org/0000-0003-3143-6811

Paula A Rochon http://orcid.org/0000-0002-5973-4151

Iliana C Lega http://orcid.org/0000-0003-4816-2589

Husam Abdel-Qadir http://orcid.org/0000-0002-7105-7931

\section{REFERENCES}

1 Islam N, Sharp SJ, Chowell G, et al. Physical distancing interventions and incidence of coronavirus disease 2019: natural experiment in 149 countries. BMJ 2020;370:370.

2 Prem K, Liu Y, Russell TW, et al. The effect of control strategies to reduce social mixing on outcomes of the COVID-19 epidemic in Wuhan, China: a modelling study. Lancet Public Health 2020;5:e261-70.

3 Alon TM, Doepke M, Olmstead-Rumsey J. The impact of COVID-19 on gender equality National Bureau of Economic Research (NBER) - Working Paper Series; 2020. https://www.nber.org/system/files/ working_papers/w26947/w26947.pdf

4 Wenham C, Smith J, Morgan R. COVID-19: the gendered impacts of the outbreak. The Lancet 2020;395:846-8. 
5 King MM, Frederickson M. The pandemic penalty: the gendered effects of COVID-19 on scientific productivity. Socius 2020;7:23780231211006977.

6 Vincent-Lamarre P, Sugimoto C, Larivière V. Nature index, 2020. Available: https://www.natureindex.com/news-blog/decline-womenscientist-research-publishing-production-coronavirus-pandemic

7 Lauer M. An early look at applications submitted during the pandemic. Open Mike., 2020NIH Extramural Nexus: National Institutes of Health (NIH) - Office of Extramural Research. Available: https://nexus.od.nih.gov/all/2020/07/28/an-early-look-atapplications-submitted-during-the-pandemic/

8 Canadian Institutes of Health Research. Canadian 2019 novel coronavirus (COVID-19) rapid research funding opportunity results, 2020. Available: https://cihr-irsc.gc.ca/e/51908.html

9 Andersen JP, Nielsen MW, Simone NL, et al. COVID-19 medical papers have fewer women first authors than expected. eLife 2020;9:e58807.

10 West JD, Jacquet J, King MM, et al. The role of gender in scholarly authorship. PLoS One 2013;8:e66212.

11 Heijstra T, Bjarnason T, Rafnsdóttir GL. Predictors of gender inequalities in the rank of full Professor. Scandinavian Journal of Educational Research 2015;59:214-30.

12 Yang S, Wolfram D, Wang F. The relationship between the author byline and contribution lists: a comparison of three general medical journals. Scientometrics 2017;110:1273-96.

13 Baerlocher MO, Newton M, Gautam T, et al. The meaning of author order in medical research. Journal of Investigative Medicine 2007;55:174-80.

14 Filardo G, da Graca B, Sass DM, et al. Trends and comparison of female first authorship in high impact medical journals: observational study (1994-2014). BMJ 2016;352:i847.

15 Wo S. 2019 Journal citation reports, 2019. Available: https://clarivate $\mathrm{com} /$ webofsciencegroup/solutions/journal-citation-reports/

16 Pachetti M, Marini B, Giudici F, et al. Impact of lockdown on Covid-19 case fatality rate and viral mutations spread in 7 countries in Europe and North America. J Transl Med 2020;18:1-7.

17 The Lancet, Lancet T. India under COVID-19 lockdown. Lancet 2020;395:1315

18 Shakespeare-Finch J, Bowen-Salter $\mathrm{H}$, Cashin $\mathrm{M}$, et al. COVID-19: an Australian perspective. Journal of Loss and Trauma 2020;25:662-72.

19 Yezli S, Khan A. COVID-19 social distancing in the Kingdom of Saudi Arabia: Bold measures in the face of political, economic, social and religious challenges. Travel Med Infect Dis 2020;37:101692.

20 Zhang Y, Jiang B, Yuan J. The impact of social distancing and EpiCenter lockdown on the COVID-19 epidemic in mainland China: a data-driven SEIQR model study. medRxiv 2020 https://www.medrxiv. org/content/10.1101/2020.03.04.20031187v1

21 Haider N, Osman AY, Gadzekpo A, et al. Lockdown measures in response to COVID-19 in nine sub-Saharan African countries. BMJ Global Health 2020;5:e003319.

22 Lerchenmueller MJ, Sorenson O, Jena AB. Gender differences in how scientists present the importance of their research: observational study. BMJ 2019;367:16573.

23 Lerchenmueller MJ, Sorenson $\mathrm{O}$. The gender gap in early career transitions in the life sciences. Res Policy 2018;47:1007-17.

24 Jena $A B$, Khullar D, Ho O, et al. Sex differences in academic rank in US medical schools in 2014. JAMA 2015;314:1149-58.

25 Lerchenmüller C, Lerchenmueller MJ, Sorenson O. LongTerm analysis of sex differences in prestigious Authorships in cardiovascular research supported by the National Institutes of health. Circulation 2018;137:880-2.

26 Viglione G. Are women publishing less during the pandemic? Here's what the data say. Nature 2020;581:365-6.

27 Mandleco B. Women in academia: what can be done to help women achieve tenure? Forum on Public Policy Online - Oxford Round Table 2010;5:1-13 https://files.eric.ed.gov/fulltext/EJ913032.pdf

28 Jolly S, Griffith KA, DeCastro R, et al. Gender differences in time spent on parenting and domestic responsibilities by high-achieving young physician-researchers. Ann Intern Med 2014;160:344-353-53.

29 Staniscuaski F, Reichert F, Werneck FP, et al. Impact of COVID-19 on academic mothers. Science 2020;368:724 https://science. sciencemag.org/content/368/6492/724.1
30 Fox MF. Women and men faculty in academic science and engineering: Social-organizational indicators and implications. American Behavioral Scientist 2010;53:997-1012.

31 Herbst THH. Gender differences in self-perception accuracy: The confidence gap and women leaders' underrepresentation in academia. SA Journal of Industrial Psychology 2020;46:1-8.

32 Theobald J, Gaglani S, Haynes MR. The association between confidence and accuracy among users of a mobile web platform for medical education. Ann Intern Med 2015;162:395-6.

33 Nomura K, Yano E, Fukui T. Gender differences in clinical confidence: a nationwide survey of resident physicians in Japan. Academic Medicine 2010;85:647-53.

34 Lind DS, Rekkas S, Bui V, et al. Competency-Based student selfassessment on a surgery rotation. Journal of Surgical Research 2002;105:31-4

35 Minter RM, Gruppen LD, Napolitano KS, et al. Gender differences in the self-assessment of surgical residents. The American Journal of Surgery 2005;189:647-50.

36 Bakken LL, Sheridan J, Carnes M. Gender Differences Among Physician-Scientists in Self-Assessed Abilities to Perform Clinical Research. Academic Medicine 2003;78:1281-6.

37 Blanch-Hartigan D. Medical students' self-assessment of performance: Results from three meta-analyses. Patient Educ Couns 2011;84:3-9.

38 Pinho-Gomes A-C, Peters S, Thompson K, et al. Where are the women? gender inequalities in COVID-19 research authorship. BMJ Glob Health 2020;5:e002922.

39 Whitelaw S, Thabane L, Mamas MA, et al. Characteristics of Heart Failure Trials Associated With Under-Representation of Women as Lead Authors. J Am Coll Cardiol 2020;76:1919-30.

40 Asghar M, Usman MS, Aibani R, et al. Sex differences in authorship of academic cardiology literature over the last 2 decades. J Am Coll Cardiol 2018;72:681-5.

41 Monroe KR, Chiu WF. Gender equality in the Academy: the pipeline problem. PS: Political Sciences \& Politics 2010;43:303-8 https:// www.cambridge.org/core/journals/ps-political-science-and-politics/ article/gender-equality-in-the-academy-the-pipeline-problem/A898 92374F3A151203CD09535BF85425

42 Ley TJ, Hamilton BH. Sociology: the gender gap in $\mathrm{NIH}$ grant applications. Science 2008;322:1472-4.

43 Hill C, Corbett C, St Rose A. Why so few? Women in science, technology, engineering, and mathematics: ERIC. Washington, DC: American Association of University Women, 2010. https://www.aauw. org/app/uploads/2020/03/why-so-few-research.pdf

44 Paulus JK, Switkowski KM, Allison GM, et al. Where is the leak in the pipeline? Investigating gender differences in academic promotion at an academic medical centre. Perspect Med Educ 2016:5:125-8.

45 Ghiasi G, Larivière V, Sugimoto $C R$. On the compliance of women engineers with a gendered scientific system. PLoS One 2015; 10:e0145931.

46 Larivière $\mathrm{V}, \mathrm{Ni} \mathrm{C}$, Gingras $\mathrm{Y}$, et al. Bibliometrics: global gender disparities in science. Nature 2013;504:211-3.

47 Aksnes DW, Rorstad K, Piro F, et al. Are female researchers less cited? A large-scale study of Norwegian scientists. Journal of the American Society for Information Science and Technology 2011;62:628-36

48 van de Weijer J, Ren G, van de Weijer J, et al. Gender identification in Chinese names. Lingua 2020;234:102759.

49 Shen $\mathrm{H}$, Helen S. Inequality quantified: mind the gender gap. Nature 2013;495:22-4 https://www.nature.com/news/inequality-quantifiedmind-the-gender-gap-1.12550

50 Lautenberger DM, Dandar VM, Raezer CL. The state of women in academic medicine: the pipeline and pathways to leadership, 20132014. Washington, DC: Association of American Medical Colleges, 2014. https://www.aamc.org/data-reports/faculty-institutions/report/ state-women-academic-medicine

51 National Postdoctoral Association (NPA). Postdoctoral scholars, gender, and the academic career pipeline: a fact sheet, 2011NPA Advance. Available: https://cdn.ymaws.com/www.nationalpostdoc. org/resource/resmgr/Docs/postdoc-gender-fact-sheet-20.pdf 